\title{
CRITICAL THINKING DAN PROBLEM SOLVING DALAM PEMBELAJARAN IPS UNTUK MENJAWAB TANTANGAN ABAD 21
}

\author{
Dyah Indraswati ${ }^{1}$, Dina Anika Marhayani ${ }^{2}$, Deni Sutisna ${ }^{3}$, Arif Widodo ${ }^{4}$, \\ Mohammad Archi Maulyda ${ }^{5}$ \\ 1, 3,4, 5 Program Studi Pendidikan Guru Sekolah Dasar (PGSD) \\ FKIP Universitas Mataram \\ Jalan Majapahit No. 62 Kota Mataram Nusa Tenggara Barat 83115 \\ ${ }^{2}$ Program Studi Pendidikan Guru Sekolah Dasar (PGSD) \\ STKIP Singkawang \\ Jalan STKIP Kelurahan Naram Singkawang Utara Kalimantan Barat 79251 \\ ${ }^{1}$ Alamat e-mail: dyahindraswati@unram.ac.id
}

\begin{abstract}
Abstrak
Artikel ini bertujuan mengkaji pentingnya critical thinking dan problem solving dalam pembelajaran IPS untuk menjawab tantangan abad 21. Metode yang dipergunakan dalam penelitian ini adalah studi literatur. 4 keterampilan abad 21 yaitu: communication, collaboration, critical thinking and problem solving, serta creativity and innovation. Tujuan pembelajaran IPS adalah mengembangkan potensi peserta didik agar terampil mengatasi masalah sosial. Pembelajaran IPS pada abad 21 harus integrative, holistic, saintifik, konstektual, tematik, efektif, kolaboratif, dan berpusat pada siswa. Pentingnya critical thinking dan Problem Solving dalam pembelajaran IPS adalah agar peserta didik dapat merangsang, menganalisis, dan melakukan sintesis tepat dimana masalah itu berada, atas inisiatif sendiri.
\end{abstract}

Kata Kunci: critical thinking; problem solving; IPS; tantangan abad 21;

\begin{abstract}
This article aims to examine the importance of critical thinking and problem solving in social studies learning to answer 21st century challenges. The method used is study of literature. 21st Century skills are communication, collaboration, critical thinking and problem solving, and creativity and innovation. The aim of social studies learning is to develop the potential of students to be skilled in dealing with social problems. Social studies learning in the 21st century must be integrative, holistic, scientific, contextual, thematic, effective, collaborative, and studentcentered. The importance of critical thinking and problem solving in social studies is that students can stimulate, analyze, and synthesize exactly where the problem is, on their own initiative.
\end{abstract}

Keywords: critical thinking; problem solving; social studies; 21st century challenge;

\section{PENDAHULUAN}

Undang-Undang Nomor 20 Tahun 2003 tentang Sistem Pendidikan Nasional menyatakan bahwa Pendidikan adalah usaha sadar dan terencana untuk mewujudkan suasana belajar dan proses pembelajaran agar peserta didik secara aktif mengembangkan potensi diri agar memiliki kekuatan spiritual keagamaan, pengendalian diri, kepribadian, kecerdasan, akhlak mulia, serta keterampilan yang 
diperlukan dirinya, masyarakat, bangsa, dan negara. Pendidikan tidak boleh diskriminatif (Arif Widodo, Dyah Indraswati, Deni Sutisna, Nursaptini, 2020). Pendidikan merupakan hak semua orang, baik anak-anak, remaja, dewasa, pria, wanita, individu normal maupun individu berkebutuhan khusus (Deni Sutisna, Dyah Indraswati, Nursaptini, Setiani Novitasari, 2020). Apabila dikaitkan dengan abad 21, muncul fenomena yang menonjol yaitu bertautnya dunia ilmu pengetahuan dan teknologi yang menyebabkan meningkatkan interaksi warga dunia secara langsung maupun tidak langsung (Widodo, Indraswati, \& Sobri, 2019).

Menurut tilaar dalam Etistika (2016: 01) paradigma baru perlu dibentuk untuk menghadapi tantangan abad 21, tantangan baru memerlukan terobosan pemikiran agar output yang dihasilkan bermutu dan dapat bersaing dengan dunia yang serba terbuka. Beberapa permasalahan di dunia pendidikan antara lain: (1) proses pembelajaran yang terlalu berorientasi pada penguasaan teori dan hafalan, menyebabkan penalaran peserta didik kurag berkembang; (2) tuntutan kurikulum yang membebankan sehingga pembelajaran kurang kontekstual dengan lingkungan sekitar; (3) kurang monitoring terhadap mutu pendidikan; (4) profesionalisme guru (Sutisna, Indraswati, \& Sobri, 2019). Upaya dalam rangka meningkatkan mutu pendidikan antara lain desain kurikulum, penentuan kompetensi, pendekatan pembelajaran, penentuan konten harus senantiasa disesuaikan dengan perkembangan situasi dan kondisi sesuai era yang terjadi. Terdapat perubahan paradigma di dalam kurikulum 2013 dimana sekarang ini pembelajaran lebih berpusat pada peserta didik dan menggunakan pendekatan pembelajaran saintifik (Widodo \& Indraswati, 2019). Sekolah harus mengajarkan tentang keterampilan hidup yang didukung dengan lingkungan belajar yang berkualitas dan layanan yang memadai (Dyah Indraswati, Arif Widodo, Aisa Nikmah Rahmatih, Mohammad Archi Maulyda, 2020).

Pendidikan abad 21 harus mampu menjawab tantangan untuk membekali peserta didik dengan 4 keterampilan atau biasa disingkat 4C yang meliputi: communication, collaboration, critical thinking and problem solving, serta creativity and innovation. Menguasai informasi dan teknologi belumlah cukup 
untuk mampu bersaing, peserta didik harus mampu mengembangkan kemampuan berpikir kritis untuk menangkal informasi yang tidak benar yang tersebar melalui media sosial. Tiga keterampilan yang harus dimiliki di abad 21 menurut p21 (Partnership for $21^{\text {st }}$ Century Learning) yaitu: life and career skills, learning and innovation skills, and information media and technology skills. Keterampilan dan ide-ide kreatif akan penemuan baru sangat dibutuhkan untuk menyelsaikan permasalahan kehidupan (Widodo, Husniati, Indraswati, Rahmatih, \& Novitasari, 2020). Senada dengan itu, Kemendikbud merumuskan paradigma pembelajaran abad 21 menuntut peserta didik untuk mencari tahu, merumuskan masalah, analitis, dan berkolaborasi menyelesaikan masalah (Litbang Kemendikbud, 2013).

Vygotsky (1978: 88) menyatakan “human learning presupposes a specific social nature and a process by which children grow into the intellectual life of those around them" artinya untuk membangun kehidupan intelektual dan proses berpikir diperlukan pengenalan lingkungan sosial. Tantangan pendidik dalam pembelajaran abad 21 antara lain mengajar di dalam masyarakat multicultural, mengonstruksi makna, pembelajaran aktif, mengevaluasi proses, dan menggunakan teknologi. UNESCO merekomendasikan empat pilar dalam pendidikan antara lain learning to know, learning to do, learning to live together, and learning to be. Karakteristik pembelajaran abad 21 harus integrative, holistic, saintifik, konstektual, tematik, efektif, kolaboratif, dan berpusat pada siswa. Tantangan pembelajaran abad 21 adalah peserta didik harus dapat mengembangkan kemampuan berpikir kritis agar dapat menyelesaikan masalah riil yang terjadi. Dalam pelaksanaan pembelajaran perlu menggunakan model yang dapat memperkuat pendekatan ilmiah agar peserta didik dapat memecahkan masalah dengan kreatif dan inovatif (Indraswati, 2018).

Apabila dikaitkan dengan Ilmu Pengetahuan Sosial, Susanto (2014:06) menyatakan (IPS) merupakan integrasi dari berbagai cabang ilmu sosial seperti sosiologi, sejarah, geografi, ekonomi, politik, hukum, dan budaya. Tujuannya untuk mempelajari gejala-gejala sosial. Tujuan utama IPS adalah mengembangkan potensi peserta didik agar peka terhadap masalah sosial dan terampil mengatasi setiap masalah yang terjadi baik yang menimpa dirinya atau masyarakat. 
Sehubungan dengan tujuan pembelajaran IPS, topik-topik sosial harus disajikan secara menarik, dan menggunakan permasalahan riil sebagai suatu konteks bagi peserta didik untuk berpikir kritis, dan mampu belajar memecahkan masalah. Namun, fakta dilapangan,pembelajaran IPS cenderung tekstual dan guru hanya sekedar mengajarkan konsep. Berdasarkan latar belakang tersebut, perlu dilakukan studi literature lebih lanjut untuk mengetahui pentingnya critical thinking dan problem solving pada pelajaran IPS untuk menjawab tantangan abad 21.

\section{METODE}

Penelitian ini menggunakan metode studi literatur dalam upaya untuk memberikan pemahaman pentingnya critical thinking dan problem solving dalam pembelajaran IPS untuk menjawab tantangan abad 21 dengan mengkaji beberapa hasil penelitian dari jurnal dan buku.

\section{HASIL DAN PEMBAHASAN}

\section{Tantangan Abad 21}

Tantangan nyata abad 21 adalah sumber daya manusia harus menguasai kompetensi utuh yang dikenal dengan keterampilan abad 21. Greenstein dalam (Sugiyarti \& Arif, 2018) mengemukakan Abad 21 menuntut peserta didik menguasai keilmuan, memiliki keterampilan metakognitif, dapat berpikir kritis dan kreatif, serta dapat berkomunikasi dan berkolaborasi. Oleh karena itu, kurikulum K-13 harus berbasis pada perkembangan peserta didik dalam menerapkan kemampuan 4C (Critical Thinking, Communication, Collaboration, and Creativity). Anies Baswedan (Republika, 2016) menjelaskan pengertian dari keterampilan 4C yang dimaksud, sebagai berikut:

1. Creativity (Kreativitas) adalah kemampuan untuk menciptakan suatu penemuan baru. Kreativitas peserta didik perlu dilatih setiap hari agar dapat menghasilkan sesuatu yang baru bagi masyarakat.

2. Critical Thinking (Berpikir kritis) adalah kemampuan peserta didik untuk menalar, mengungkapkan, menganalisis, dan memecahkan masalah. Pada era 
globalisasi, critical thinking digunakan untuk memfilter beragam informasi, karena banyaknya hoax yang tersebar dikalangan masyarakat.

3. Communication (Komunikasi) adalah kemampuan peserta didik untuk menyampaikan, menanggapi, dan menggunakan informasi agar dapat terhubung dengan orang lain sehingga tercapai suatu perubahan kearah kemajuan.

4. Collaboration (Kolaborasi) adalah kemampuan peserta didik untuk bekerja sama dan bertanggung jawab dengan orang lain sehingga dapat menghasilkan sesuatu yang berguna bagi masyarakat. Keterampilan ini digambarkan dalam skema sebagai berikut:

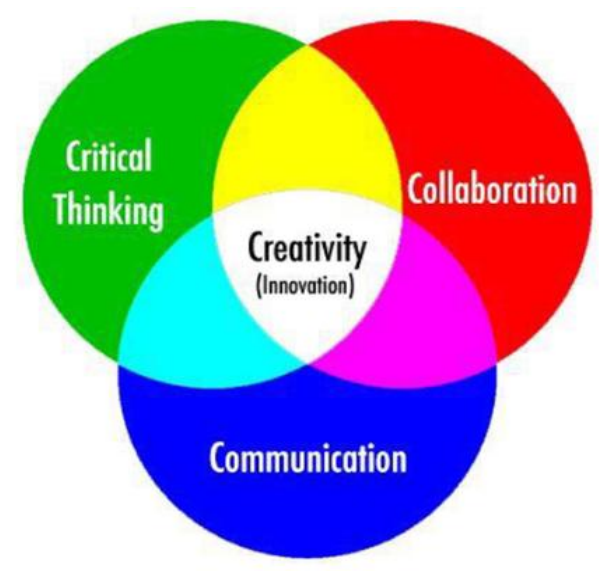

\section{Gambar 1. Keterampilan 4C di abad 21}

Keterampilan Abad 21 (Triling and Fadel, 2009: 47):

1. Life and Career Skiils (Keterampilan Hidup dan Berkarir):

a. Fleksibilitas dan Adaptabilitas: pendidikan harus mengakomodasi peserta didik agar mampu belajar secara berkelompok.

b. Memiliki inisiatif: peserta didik mampu mengatur diri sendiri, mengelola waktu, dan belajar secara independent.

c. Interaksi social dan budaya: peserta didik dapat berinteraksi dalam kelompok yang heterogen.

d. Produktivitas dan Akuntabilitas: peserta didik dalam membuat produk yang inovatif. 
e. Kepemimpinan dan tanggung jawab: peserta didik mampu memimpin dan bertanggung jawab pada orang lain.

2. Learning and Innovation Skills (Keterampilan Belajar dan Berinovasi)

a. Berpikir kritis dan memecahkan masalah: peserta didik mampu berpikir secara rasional, menganalisis penyebab suatu permasalahan, mengambil keputusan, dan memecahkan masalah.

b. Komunikasi dan Kolaborasi: peserta didik mampu berkomunikasi dan berkolaborasi dengan teman-temannya.

c. Kreativitas dan Inovasi: peserta didik mampu berpikirsecra kreatif, bekerja, dan menciptakan inovasi baru.

3. Information Media and Technology Skills (Keterampilan teknologi dan media informasi):

a. Literasi informasi: peserta didik dapat mencari informasi secara efektif dan efisien, menyaring informasi yang diterima, dan menggunakannya untuk menambah wawasan serta mengatasi masalah.

b. Literasi media: peserta didik dapat menentukan dan mengembangkan media untuk berkomunikasi.

c. Literasi ICT: peserta didik dapat melakukan analisis dan menciptakan media untuk komunikasi. Literasi adalah kemampuan dasar yang dibutuhkan dalam membentuk kompetensi global (Widodo, A., Indraswati, D., Erfan, M., Maulyda, M. A., \& Rahmatih, 2020).

Wagner dalam Hidayah Ratna (2017: 127) mengemukakan ada tujuh keterampilan yang dibutuhkan peserta didik pada abad 21 yaitu (1) berpikir kritis dan mengatasi masalah, (2) kolaborasi dan kepemimpinan, (3) ketangkasan dan kemampuan beradaptasi, (4) inisiatif dan memiliki jiwa entrepreneur, (5) komunikasi efektif, (6) mengakses dan analisis informasi, (7) imajinasi.

US-Based Apollo Education Group mengkategorikan keterampilan yang diperlukan pada abad ke-21 meliputi berpikir kritis, kepemimpinan, komunikasi, beradaptasi, kolaborasi, akuntabilitas dan produktivitas, inovasi, kewarganegaraan global, jiwa entrepreneurship, mengakses, menganalisis, dan mensintesis informasi. 
Triling and Hood (1999: 21) mengemukakan percepatan pengetahuan saat ini berlangsung luar biasa dengan dukungan teknologi digital dan media. Oleh karena itu, kegiatan pembelajaran harus disesuaikan dengan kondisi tersebut. Bahan pembelajaran harus didesain secara lebih konstektual agar peserta didik dapat siap dengan tantangan dan berkolaborasi menciptakan solusi untuk memecahkan masalah dari informasi yang didapatkan.

Pendidikan berperan penting dalam pengembangan kompetensi peserta didik sesuai dengan tantangan abad 21. Hal ini dapat didasari pertimbangan sebagai berikut: Pertama, kegiatan pembelajaran merupakan bentuk interaksi antara peserta didik dengan sumber belajar, baik yang bersifat by design maupun by utilization yang mengarah pada pembentukan dan pengembangan kompetensi tertentu sebagai sinergi antara ranah pengetahuan, sikap, dan keterampilan. Kedua, pendidikan mewujudkan potensi peserta didik secara optimal dengan dinamika perubahan di masyarakat. Ketiga, pendidikan memfasilitasi pembentukan dan pengembangan kompetensi individu sebagai prasyarat kecakapan hidup yang diperlukan dalam konteks kehidupan pada tingkat keluarga dan masyarakat.

\section{Critical Thinking (Berpikir Kritis)}

Berpikir kritis adalah kemampuan yang melampaui hafalan. Ketika peserta didik berpikir kritis, mereka didorong untuk mempertanyakan hipotesis, menganalisis, mensintesis peristiwa. Berpikir kritis membuat peserta didik melangkah lebih jauh dengan mengembangkan hipotesis baru dan mengujinya terhadap fakta. (Karakoc, 2016).

Keterampilan berpikir kritis merupakan salah satu komponen berpikir tingkat tinggi yang menjadi focus pembelajaran abad-21. Bagan hirarki berpikir adalah sebagai berikut. 


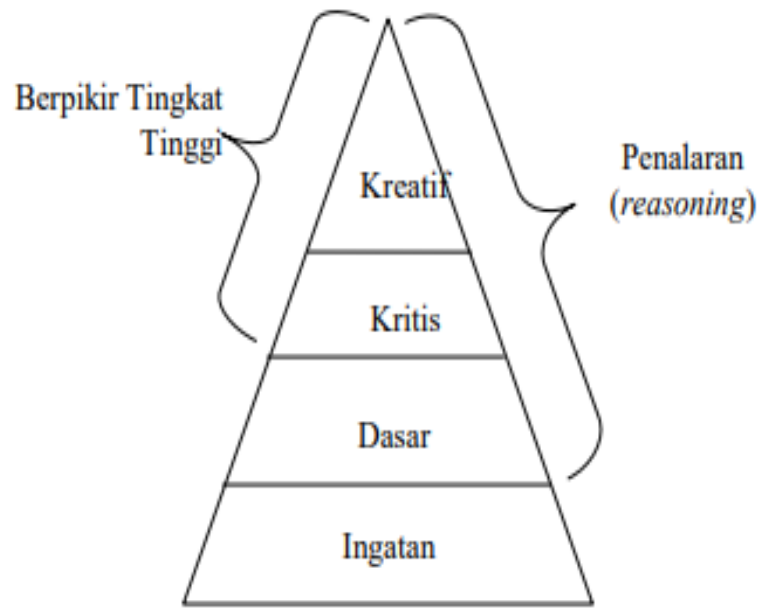

\section{Gambar 2. Hirarki Berpikir (Krulik dan Rudnick)}

Hirarki dimulai dari ingatan, berpikir dasar, berpikir kritis, dan berpikir kreatif. Penalaran (reasoning) adalah berpikir yang tingkatannya di atas ingatan, sedangkan berpikir tingkat tinggi meliputi berpikir kritis dan kreatif. Onion (2009:2): mengatakan "Critical thinking is a way of thinking and skills carried out to obtain information consciously, systematically, and with logical consideration of deciding what to do. Critical thinking leads to valid conclusions that are resistant to criticism".

Hal ini senada dengan pendapat Ronald A. Styron (2014) yang mengemukakan bahwa berpikir kritis adalah proses disiplin intelektual dari aktivitas dan keterampilan dalam mengkonsep, menerapkan, menganalisis, mensintesis, dan mengevaluasi dari informasi yang dikumpulkan dari pengamatan, refleksi, penalaran, atau komunikasi sebagai panduan dalam melakukan tindakan.

Benjamin Bloom (1956) membagi proses berpikir menjadi tiga domain, yaitu kognitif, afektif, dan psikomotor. Domain kognitif menekankan pada hasil intelektual yang dibagi menjadi 6 level yaitu: pengetahuan, comprehension, aplikasi, analisis, sintesis, dan evaluasi. Analisis, sintesis, dan evaluasi dianggap sebagai pemikiran kritis. 
Menurut Bahr (2010), berpikir kritis memiliki dua makna yaitu pemikiran tingkat tinggi dan kritik social. Berpikir kritis adalah tentang memeriksa asumsi, tidak menerima begitu saja informasi yang diterima, dan tentang memahami konsep dengan jelas sehingga siswa dapat berpikir jernih tentang apa yang mereka konsumsi. Peserta didik mengembangkan gagasan yang jelas tentang apa yang mereka lakukan dan mengapa dan kemudian mereka sendiri yang terlibat dalam pemikiran kritis tersebut.

Beberapa pendapat diatas sejalan dengan tuntutan terselenggaranya proses pendidikan yang mampu mengembangkan kemampuan berpikir kritis peserta didik, karena itu akan sangat berpengaruh terhadap keberhasilan hidup seseorang. Peserta didik yang memiliki keterampilan berpikir kritis cenderung dapat mengidentifikasi informasi yang relevan, memisahkan informasi yang tidak relevan, dan memanfaatkan informasi tersebut untuk mencari solusi permasalahan dan mengambil keputusan.

Ken Changwong, dkk (2018:46) dalam penelitiannya yang berjudul "critical thinking skill development: Analysis of a new learning management model for Thai high schools" menyimpulkan bahwa all students at all academic levels will clearly benefit from curricula steeped in critical thinking strategies and practice. Students who master the ability to think critically and insightfully will perform better academically in their current high school setting, and will also be better prepared for the rigors and enhanced academic expectations in college.

Pendidikan di Indonesia perlu menemukan cara yang lebih efektif untuk mempersiapkan peserta didik memenuhi tuntutan berpengetahuan digital yang aktif dengan keterampilan berpikir kritis. Peserta didik harus mampu berpikir kritis dan memecahkan masalah apapun secara kreatif, menawarkan pengetahuan sebagai solusi yang potensial,dan memiliki kepercayaan diri untuk melakukannya. Guru harus bertanggung jawab untuk proses ini, karena peserta didik perlu sering berlatih pada praktik berpikir kritis. 


\section{Problem Solving}

Menurut Walgito dalam Maulidya (2018) problem adalah sesuatu yang timbul karena adanya pertentangan antara keadaan satu dengan keadaan yang lain. Problem juga dapat diartikan sebagai ketidaksesuaian antara yang seharusnya terjadi dengan sesuatu yang nyata. Problem solving diartikan sebagai proses mental dalam menemukan masalah dan memecahkannya berdasar data dan informasi akurat, sehingga dapat diambil kesimpulan yang tepat.

Kartono (1985:142-143) mengemukakan prinsip problem solving adalah:

1. Keberhasilan dalam memecahkan masalah.

2. Pemakaian informasi dalam memecahkan masalah.

3. Mencari alternatif jalan keluar sebagai titik tolak pemecahan masalah.

4. Menyadari penyebab permasalahan terlebih dahulu.

5. Menciptakan ide-ide baru.

6. Menjadikan situasi masalah sebagai situasi pilihan.

Faktor yang mempengaruhi problem solving antara lain: motivasi, kepercayaan dan sikap, kebiasaan, emosi, kesalahan. Langkah-langkah problem solving meliputi menyadari adanya masalah, mengumpulkan data, mengevaluasi hipotesis, penyelidikan literatur, eksperimen dan pembuatan kesimpulan.

Fokus utama dalam pembelajaran adalah mengajarkan peserta didik berpikir, menggunakan rasional, dan menjadi problem solver yang baik. Penyelesaian masalah sebagai hasil pembelajaran sangat penting bagi kehidupan, karena manusia selalu dipenuhi dengan masalah dalam kesehariannya. Jonassen dalam (Susiana, 2012) menyatakan pentingnya problem solving antara lain:

1) Authenticity, penyelesaian masalah adalah kegiatan yang dapat ditemui dimanapun berada.

2) Relevance masalah khususnya yang diberikan kepada peserta didik untuk dipecahkan.

3) Penyelesaian masalah membutuhkan telaah mendalam.

4) Pembelajaran yang dibangun dari masalah merupakan pembelajaran bermakna. 
Menurut Gick dalam Susiana (2012:74) Ada tiga tahap dalam penyelesaian masalah yaitu mengonstruksi masalah, mencari penyelesaian, dan menggunakan/ mengimplementasi penyelesaian. Skemanya dapat dilihat pada gambar berikut.

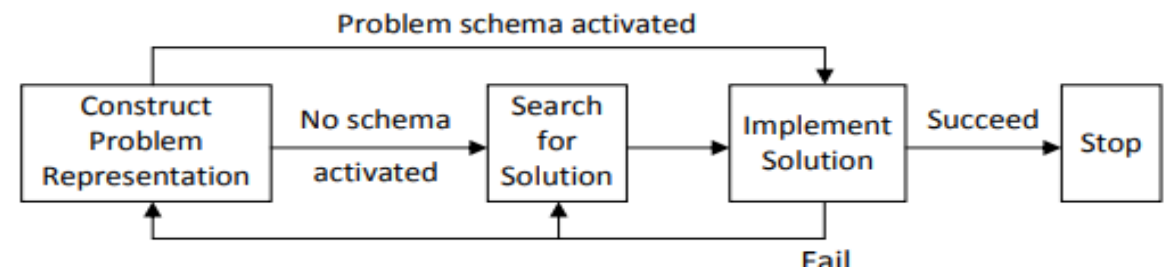

Gambar 3. Skema penyelesaian masalah dari Gick

Polya dalam Suherman (2003: 91) mengungkapkan ada 4 tahap dalam penyelesaian masalah antara lain memahami masalah, merencanakan penyelesaian, melaksanakan rencana, dan evaluasi terhadap segala tindakan.

Problem Solving menurut David Johnson dan Johnson dalam (Winarso, 2014) dapat dilakukan dalam pembelajaran melalui kelompok dengan prosedur antara lain:

1. Identifikasi Masalah

a. Sampaikan kepada peserta didik tentang permasalahan yang terjadi di lingkungan sekitar, kemudian peserta didik diminta untuk merumuskan masalah.

b. Minta peserta didik untuk mengemukakan penjelasan dari pendapatnya. Dengan demikian, dapat dihapus rumusan masalah yang kurang relevan,kemudian memilih satu rumusan masalah yang paling tepat.

2. Mendiagnosis masalah

Mendiskusikan penyebab dari timbulnya masalah.

3. Merumuskan alternative strategi

Menemukan berbagai macam alternative cara penyelesaian masalah.

4. Menentukan dan menerapkan strategi.

5. Mengevaluasi keberhasilan strategi.

\section{Critical Thinking dan Problem Solving dalam Pembelajaran IPS}

IPS merupakan perpaduan dari berbagai macam disiplin ilmu seperti 
sejarah, ekonomi, geografi, dan sosiologi yang disusun secara sistematis dan terintegrasi. IPS banyak menekankan pada hubungan antara manusia dengan masyarakat. Tujuan utama IPS adalah membantu peserta didik mengembangkan kemampuan membuat keputusan yang rasional dan informatif bagi kebaikan masyarakat.

Ilmu Pengetahuan Sosial (IPS) mengedepankan pengembangan kompetensi peserta didik yang menuntut pada kemampuan berpikir kritis untuk menyelesaikan masalah sosial. Hal ini sejalan dengan tujuan mata pelajaran IPS menurut National Council for The Social Studies (NCSS) dalam (Dan, Menurut, \& Siswa, n.d.) "social studies program have responsibility to prepare young people to identify, understands and work to solve problems that face our increasingly diverse nation and interdependence world. Over the past several decades, the professional consensus has been that such programs ought to include goals in the broad areas of knowledge, democratic value, and skills. Program that combine that acquisition of knowledge and skill with the application of democratic values of life, through social participation present an ideal balance in social studies. It is essential that these major goals be viewed an equally important. The relationship among knowledge, values, and skills is one of mutual support".

Sunal dan Hass dalam (Dan, Menurut, \& Siswa, n.d) menyatakan ada 5 prinsip pembelajaran yang powerful yaitu bermakna, terpadu, menantang, aktif, dan berbasis nilai. Upaya peningkatan kemampuan berpikir kritis peserta didik dengan menerapkan model pembelajaran yang relevan dengan aktivitas berpikir kritis misalnya model pembelajaran problem solving.

Suparno dalam Trianto (2009: 18) menjelaskan ada empat aspek dalam pembelajaran konstruktivis yang bisa diterapkan dalam pembelajaran IPS antara lain:

1. Peserta didik membangun sendiri pengetahuannya, baik secara personal maupun social.

2. Pengetahuan tidak dipindahkan dari guru ke peserta didik, kecuali dengan keaktifan peserta didik dalam menalar. 
3. Selalu terjadi perubahan konsep ilmiah karena peserta didik aktif mengonstruksi terus-menerus.

4. Guru berperan sebagai fasilitator agar proses mengonstruksi peserta didik berjalan lancer

Angelo (1995: 6) mengemukakan ada 5 indikator perilaku yang sistematis dalam berpikir kritis yaitu:

1. Keterampilan menganalisis

2. Keterampilan mensitesis

3. Keterampilan mengenal dan memecahkan masalah

4. Keterampilan menyimpulkan

5. Keterampilan mengevaluasi dan menilai

Penelitian yang dilakukan oleh Waring, Scott M. \& Krik yang berjudul "Developing Critical and Historical Thinking Skills in Middle Grades Social Studies" dalam Hestiningsih (2015: 74) menunjukkan penting sekali mengembangkan kemampuan berpikir kritis. Penelitian ini menunjukkan mengembangkan berpikir kritis dapat dilakukan dengan pemecahan masalah, membuat hipotesis, memperkirakan kemungkinan, dan mengambil keputusan. Hal ini perlu diajarkan disekolah supaya dalam keseharian mereka dapat memutuskan tindakan apa yang harus dilakukan.

Pentingnya critical thinking dan Problem Solving dalam pembelajaran IPS adalah agar peserta didik dapat merangsang, menganalisis, dan melakukan sintesis tepat dimana masalah itu berada, atas inisiatif sendiri. Dalam pembelajaran IPS, peserta didik dituntut memiliki kemampuan melihat sebab akibat atau relasi dari berbagai informasi yang didapat sehingga dapat menemukan kunci pemecahan masalah.

\section{SIMPULAN}

Dengan menerapkan proses pembelajaran yang berbasis pada critical thinking dan problem solving, maka pembelajaran IPS yang dilakukan akan memiliki kelebihan sebagai berikut: 
1. Pembelajaran semakin relevan dengan kehidupan (konstektual).

2. Peserta didik akan terbiasa menghadapi dan memecahkan masalah secara terampil.

3. Pembelajaran yang dilakukan bukan hanya sebatas hafalan tapi lebih bermakna bagi peserta didik.

4. Memberikan tantangan kepada peserta didik dan mereka akan puas dengan ide baru.

5. Peserta didik memiliki kemampuan berpikir kritis dan mudah beradaptasi dengan lingkungan baru.

6. Peserta didik mengevaluasi pemahaman dan mengidentifikasi alur berpikirnya.

Dari uraian diatas, dapat dipahami bahwa critical thinking dan problem solving pada pembelajaran IPS membuat peserta didik mampu memiliki pemahaman terhadap masalah secara mendalam, mensintesis, dan menarik kesimpulan untuk dapat memecahkan masalah-msalah social secara terarah, evaluative, dan reflektif untuk menjawab tantangan abad 21.

\section{DAFTAR PUSTAKA}

Angelo, T. A. (1995). "Classroom assessment for critical thinking". Teaching of Psychology, 22, 6-7.

Arif Widodo, Dyah Indraswati, Deni Sutisna, Nursaptini, S. N. (2020). Identifikasi Bakat Peserta Didik Berkebutuhan Khusus (Pdbk) Di Madrasah Inklusi Kabupaten Lombok. Jurnal Pendidikan Inklusi (JPI), $3(2)$, $102-116$. https://doi.org/http://dx.doi.org/10.26740/inklusi.v3n2.p102-116.

Bahr, Nan. (2010). "Thinking Critically about Critical Thinking in Higher Education". International Journal for the Scholarship of Teaching and Learning (Vol. 4: No. 2, Artikel 9).

Bloom, B., S. (1956). Taxonomy of Educational Objectives, Handbook I: The Cognitive Domain. New York, NY: David McKay Co Inc.

BSNP. (2010). “Paradigma Pendidikan Nasional Abad XXI". [Online]. Tersedia: http://www.bsnpindonesia.org/id/wpcontent/uploads/2012/04/LaporanBSNP-2010.pdf. 
Changwong, K. (2018). "Critical thinking skill development: Analysis of a new learning management model for Thai high schools". 11, 37-48. https://doi.org/10.14254/20718330.2018/11-2/3.

Depdiknas. (2003). Undang-Undang RI Nomor 20, Tahun 2003, tentang Sistem Pendidikan Nasional.

Dan, S., Menurut, P., \& Siswa, S. (n.d.). Perbedaan berpikir kritis antara model problem solving dan posing menurut sikap siswa 1). (1).

Deni Sutisna, Dyah Indraswati, Nursaptini, Setiani Novitasari, M. S. (2020). Penerapan Program Pendidikan Inklusi Di SDN 1 Sangkawana Lombok Tengah. Progres Pendidikan, 1(2), 115-127.

Dyah Indraswati, Arif Widodo, Aisa Nikmah Rahmatih, Mohammad Archi Maulyda, M. E. (2020). Implementasi Sekolah Ramah Anak Dan Keluarga Di Sdn 2 Hegarsari, Sdn Kaligintung, Dan Sdn 1 Sangkawana. JKKP: Jurnal Kesejahteraan Kelaurga Dan Pendidikan, 7(April), 51-62. https://doi.org/: http://doi.org/10.21009/JKKP.071.05.

Hestiningsih, Nur \& Sugiharsono. (2015). "Peningkatan Kemampuan Berpikir Kritis Peserta Didik Pembelajaran IPS Melalui Metode Problem Solving Berbantuan Media Informasi”. Jurnal Harmoni Sosial: Jurnal Pendidikan IPS Volume 2, No 1, Maret 2015 (71-85).

Hidayah, Ratna, dkk. (2017) "Critical Thinking Skill: Konsep dan Indikator Penilaian”. Jurnal Taman Cendekia. Vol.01 No. 02 December 2017.

https://republika.co.id/berita/pendidikan/eduaction/16/02/06/o24uep284-strategi4c-untuk-tingkatkan-mutu-pendidikan diakses tanggal 13 September 2019 pukul 15.00 WITA.

Indraswati, D. (2018). Efektivitas Model Pembelajaran Kooperatif Tipe Numbered Heads Together ( NHT ) Terhadap: Kompetensi Sikap Siswa, Kompetensi. Journal Research and Analysis: Economy, 1(2), 52-58. Retrieved from https://journal.stkipsingkawang.ac.id/index.php/JRAE/article/view/953.

Karakoç, M. (2016). “The Significance Of Critical Thinking Ability In Terms Of Education". International Journal of Humanities and Social Science, 6(7), $81-84$.

Kartono, Kartini. (1985). Bimbingan dan Dasar-Dasar Pelaksanaannya. Jakarta: CV Rajawali.

Kemendikbud. Penyelenggaraan Pendidikan Sistem Ganda pada Sekolah Menengah Kejuruan. Jakarta: Direktorat Pendidikan Menengah Kejuruan. 
Kemendikbud. No.0490/U/1992. Sekolah Menengah Kejuruan. Jakarta: Departemen Pendidikan dan Kebudayaan.

Maulidya, Anita. (2018). "Berpikir dan Problem Solving:. Jurnal Pendidikan Bahasa dan Sastra Arab. Volume 4 No 1.

Onions, P. (2009). "Thinking Critically. An Introduction, Working Paper". .http://www.patrickonions.org/docs/academic/2009\%20Thinking\%20critica lly.pdf. [12 September 2019].

P21. (2008). 21st Century Skills, Education \& Competitiveness. Washington DC, Partnership for 21st Century Skills.

Ronald A. Styron, Jr. (2014). "Critical Thinking and Collaboration: A Strategy to Enhance Student Learning". Systemics, Cybernetics, And Informatics Journal. Volume 12 Number 7. 1690-4524.

Sugiyarti, L., \& Arif, A. (2018). Pembelajaran Abad 21 Di Sd. Prosiding Seminar Dan Diskusi Nasional Pendidikan Dasar 2018, 439-444.

Suherman, E., dkk. (2003). Strategi Pembelajaran Matematika Kontemporer. Bandung: Universitas Pendidikan Indonesia.

Susanto, Ahmad. (2014). Pengembangan Pembelajaran IPS di Sekolah Dasar. Jakarta: Kencana.

Susiana, E. (2012). IDEAL Problem Solving dalam Pembelajaran Matematika. Kreano: Jurnal Matematika Kreatif-Inovatif, 1(2), 73-82. https://doi.org/10.15294/kreano.v1i2.1491

Sutisna, D., Indraswati, D., \& Sobri, M. (2019). Keteladanan Guru sebagai Sarana Penerapan Pendidikan Karakter Siswa. Jurnal Pendidikan Dasar Indonesia, 4(2), 29-33. https://doi.org/http://dx.doi.org/10.26737/jpdi.v4i2.1236

Trianto.2009. Mendesain Model Pembelajaran Inovatif-Progresif. Konsep: Landasan, dan Implementasi pada Kurikulum Tingkat Satuan Pendidikan. Jakarta: Kencana.

Trilling, Bernie and Fadel, Charles. 2009. 21 st Century Skills: Learning for Life in Our Times, JohnWiley \& Sons, 978-0-47-055362-6.

Trilling, Bernie and Hood, Paul. 1999. Learning, Technology, and Education Reform In The Knowledge Age, (Online), (https://www.wested.org/online_pubs/ learning_technology.pdf.), diakses tanggal 11 Mei 2016.

Widodo, A., Indraswati, D., Erfan, M., Maulyda, M. A., \& Rahmatih, A. I. (2020). Profil minat baca mahasiswa baru PGSD Universitas Mataram. Premiere 
Educandum: Jurnal Pendidikan Dasar Dan Pembelajaran, 10(February), 34-48. https://doi.org/10.25273/pe.v10i1.5968.

Widodo, A., Husniati, H., Indraswati, D., Rahmatih, A. N., \& Novitasari, S. (2020). Prestasi belajar mahasiswa PGSD pada mata kuliah pengantar pendidikan ditinjau dari segi minat baca. Jurnal Bidang Pendidikan Dasar, 4(1), 26-36. https://doi.org/https://doi.org/10.21067/jbpd.v4i1.3808.

Widodo, A., \& Indraswati, D. (2019). Analisis Konten HOTS dalam Buku Siswa Kelas V Tema 6 " Panas dan Perpindahannya " Kurikulum 2013. Madrasah, 12(1), 1-13. https://doi.org/http://dx.doi.org/10.18860/mad.v12i1.7744.

Widodo, A., Indraswati, D., \& Sobri, M. (2019). Analisis Nilai-Nilai Kecakapan Abad 21 Dalam Buku Siswa SD/MI Kelas V Sub Tema 1 Manusia dan Lingkungan. Jurnal Tarbiyah: Jurnal Ilmiah Kependidikan, 8(2), 125-133. https://doi.org/10.18592/tarbiyah.v8i2.3231.

Wijaya, Etistika Yuni.,dkk. 2016. Transformasi Pendidikan Abad 21 Sebagai Tuntutan Pengembangan Sumber Daya Manusia di Era Global. Prosiding Seminar Nasional Pendidikan Matematika, Universitas Kanjuruhan Malang Volume 1 Tahun 2016.

Winarso, W. (2014). Problem Solving , Creativity dan Decision Making Dalam Pembelajaran Matematika Widodo Winarso. 3(1).

Vygostsky, L.S. (1978). Mind in society the development of higher psychological processes. Diedit oleh Michael Cole et al. USA: Harvard University Press 